\title{
Cohort-Specific Experiences of Industrial Decline and Intergenerational Income Mobility
}

\author{
Nathan Seltzer*, University of California, Berkeley
}

Draft: $7 / 1 / 2021$

\begin{abstract}
The U.S. manufacturing industry has long been regarded as the economic engine that built and sustained the middle class. In recent decades, this pillar of economic opportunity has eroded substantially. Though much has been written about the decline of manufacturing sectors in U.S. communities, the potential consequences for economic mobility, and stratification processes more generally, remain largely unexplored. In this study, I develop a conceptual framework linking the study of labor market change to economic stratification. I examine how structural changes to U.S. labor markets have altered opportunities for economic advancement in the U.S. I focus the analysis on birth cohorts in the 1980s, whose labor market entry spans the large-scale erosion of the manufacturing industry in the 2000s. I find strong evidence that declines in manufacturing employment have contributed to growing geographic disparities in upward intergenerational income mobility. Children raised in counties that experienced large contractions in manufacturing industries throughout adolescence experienced large economic penalties in adulthood via reduced levels of upward mobility. The results demonstrate how longterm macroeconomic changes can disrupt and redistribute opportunities within societies.
\end{abstract}

\section{KEYWORDS}

Deindustrialization, Intergenerational Income Mobility, Manufacturing Decline, Economic Stratification

*Nathan Seltzer, Department of Demography, Berkeley Center on the Economics and Demography of Aging, University of California, Berkeley. Email: nseltzer@berkeley.edu

The author is grateful for feedback from Jenna Nobles, Rourke O'Brien, Myra Marx Ferree, Christine Schwartz, Jim Raymo, Mike Hout, Siwei Cheng, and Katie Jajtner. This research was supported by training grant T32 AG00129 awarded to the Center for Demography of Health and Aging at the University of Wisconsin-Madison by the National Institute on Aging. All errors are the author's own. 


\section{Cohort-Specific Experiences of Industrial Decline and Intergenerational Income Mobility \\ Nathan Seltzer, University of California, Berkeley}

\section{BACKGROUND}

The U.S. manufacturing industry has long been regarded as the economic engine that built and sustained the middle class (Green and Sanchez 2007; Janoski, Luke, and Oliver 2014; Moretti 2012). For much of the $20^{\text {th }}$ century, employment in manufacturing industries acted as a ladder that raised poor- and working-class families and individuals into the middle class through stable full-time and well-paying jobs. Yet, in recent decades, this pillar of economic opportunity has rapidly declined (Acemoglu and Autor 2011; Kalleberg 2009). In 1980, one out of four workers were employed in a goods-producing industry; by the start of 2020, the share had dropped to one in ten workers. ${ }^{1}$ Although employment in manufacturing modestly increased in the decade following the end of the Great Recession in 2009, wages for new production jobs were substantially lower than in prior decades and workers were less likely to be covered by a union contract (Bureau of Labor Statistics 2020; Jacobs et al. 2016). The rapid pace of job destruction in manufacturing industries is further compounded by the lack of wage growth in the expanding low-skill service sector as well as by the rise of nonstandard and contingent work (Hollister 2011; Kalleberg 2018; Schneider and Harknett 2019). Workers who lack a bachelor's degree in this new occupational environment have progressively found their employment opportunities constrained and their prospects for upward mobility diminished (Autor and Dorn 2013; Autor, Katz, and Kearney 2006).

\footnotetext{
${ }^{1}$ Authors calculations using BLS data from the Federal Reserve Bank of St. Louis (FRED).
} 
The decline of manufacturing in the U.S. is now popularly viewed as the "cause" of many social, demographic, and political changes that have occurred in recent decades (Case and Deaton 2020; Goldstein 2017; Hochschild 2017; Packer 2013). Social scientific and journalistic accounts suggest that the economic deterioration initiated by manufacturing decline in traditional blue-collar communities is associated with the rise of "deaths of despair" from alcohol, drugs, and suicide (Case and Deaton 2015; Monnat 2019; Venkataramani et al. 2020). In a similar line of inquiry, researchers have also documented how the rearrangement of opportunities in the U.S. labor market has contributed to shifts in other demographic processes, including fertility behavior and migration patterns, vis-à-vis increases in economic insecurity (Charles, Hurst, and Notowidigdo 2018; Greenland, Lopresti, and Mchenry 2019; Seltzer 2019). Despite the extensive scholarly and public interest in understanding how labor market changes might be impacting social and demographic trends, we know little about how this postindustrial transition has impacted intergenerational mobility processes.

In the present study, I develop a conceptual framework for examining how deindustrialization in U.S. communities has reshaped the upward mobility prospects of birth cohorts born during the 1980s. I focus on birth cohorts born during this period because they entered the labor force during a pivotal moment in the history of U.S. deindustrialization (the late 1990s and early 2000s) that coincided with the start of what would ultimately be the loss of approximately 5.7 million jobs in the manufacturing sector over the course of the 2000s (Atkinson et al. 2012). ${ }^{2}$ In relative terms, the percentage of jobs in the manufacturing sector dropped from $15.5 \%$ of all jobs in the U.S. labor market to $10.5 \%$ of all jobs in the U.S. labor

\footnotetext{
${ }^{2}$ About 3.4 million of these lost manufacturing jobs (or about $60 \%$ ) disappeared prior to the start of the Great Recession in 2007.
} 
market between 2000-2010. During this same period, the manufacturing sector went from representing $70 \%$ of all jobs in goods-producing industries to $65 \%$ of all jobs in goods-producing industries. ${ }^{3}$ Linking subnational business records on industrial change with county-level and cohort-specific estimates of intergenerational income mobility, I examine how both short- and long-term changes in manufacturing employment in the U.S. have altered economic opportunity structures across communities.

I ask two questions: First, to what extent does variation in manufacturing employment explain spatial differences in intergenerational mobility across local labor markets? That is, do communities that have maintained a thriving manufacturing sector provide better opportunities for new labor market entrants than communities that have little or no remaining employment in manufacturing industries? Second, do community-specific histories of industrial change and restructuring explain differences in intergenerational mobility outcomes?

The findings offer empirical evidence of the sizable role of industrial change on economic opportunity and provide two contributions to literature on social stratification and life course trajectories. First, children from the 1980-1988 birth cohorts who lived in counties with a higher share of manufacturing employment upon labor force entry - operationalized as either the county-level share of employment or annual earnings concentrated in manufacturing industries at age 18 - experienced more upward income mobility than those who lived in counties with a lower share of manufacturing upon labor force entry. Second, children from these birth cohorts who lived in counties that experienced larger contractions in manufacturing throughout their

\footnotetext{
${ }^{3}$ Author's calculations of data from the Federal Reserve Bank of St. Louis; MANEMP and USGOOD series'. I focus on the manufacturing sector specifically because it has historically represented and currently represents the majority of all jobs in goods-producing industries. In contrast to employment declines in the manufacturing sector, other goods-producing industrial sectors (e.g. oil and gas extraction and construction) experienced employment growth during the 1990s and 2000s.
} 
adolescence faced larger economic penalties in adulthood via reduced levels of upward intergenerational mobility. Overall, the findings of this study demonstrate how long-term - but ongoing - structural changes to the labor market can disrupt and redistribute opportunities.

\section{Industrial Change and Intergenerational Mobility Processes}

Why might we expect the decline of the U.S. manufacturing sector to be associated with reductions in upward mobility? First, rising job displacement from manufacturing industries is associated with unstable employment and/or underemployment as well as reductions in shortand long-term earnings (Carrington and Fallick 2015; Couch et al. 2018; Fallick 1996; Parrado, Asena, and Wolff 2007). Worker movement across occupations and industries became increasingly more common during the second half of the $20^{\text {th }}$ century (Jarvis and Song 2017; Parrado et al. 2007) and displacement-induced job moves from manufacturing to other industries are associated with substantial earnings losses (Cha and Morgan 2010). Overall, the decline in manufacturing jobs has destabilized stable, well-paying occupational career trajectories, thereby reducing the availability of occupational opportunities for upward movement.

Second, the geography of manufacturing decline varies considerably across and within regions (Green and Sanchez 2007; Moretti 2012), which might exacerbate pre-existing spatial trends in intergenerational mobility (Curtis et al. 2019). Between 1980-2010, the Northeast experienced the sharpest losses in manufacturing employment while the West Coast experienced slight increases in manufacturing employment (Helper, Krueger, and Wial 2012). While the Midwest had a slight resurgence in manufacturing employment growth in the 1990s after a decline in the 1980s, it then experienced substantial losses in the 2000s along with all other regions of the country. Within regions and states during this time period, manufacturing jobs shifted from metropolitan areas to small metropolitan and non-metropolitan areas (Helper et al. 
2012). On the surface, these trends correlate with the geography of upward intergenerational mobility: findings by Chetty et al. (2014) indicate that regions such as the Southeast and Rust Belt have lower upward income mobility outcomes than regions such as the Northeast, the Great Plains, and the West Coast. There is also substantial within-state, and even within-commuting zone, variation in most states, but particularly in states such as Texas, Missouri, and Ohio. Yet, prior studies have not sought to rigorously investigate whether there is any statistical relationship between these two geographic trends.

\section{Trends in Intergenerational Income Mobility}

This analysis is motivated by recent temporal and geographic trends in intergenerational income mobility for birth cohorts born in the second half of the $20^{\text {th }}$ century. Stratification researchers rely on indicators of intergenerational income mobility, such as the intergenerational elasticity (IGE) and rank-rank slope, because they provide a straightforward description of change in the opportunity structure of societies over time as well as a comparison in economic opportunity across and within societal and geographic contexts (Bloome 2015; Cheng and Song 2019; Hout 2015). Higher levels of income mobility imply that social origins do not necessarily portend social destinations, while lower levels of income mobility indicate a deterministic social structure where early life circumstances of advantage or disadvantage predict later life outcomes (Black and Devereux 2010; Bloome and Dyer 2018; Hout 2015).

The majority of studies on long-term trends in relative intergenerational mobility suggest little if any change in intergenerational income mobility for birth cohorts born during the several decades following World War II (Lee and Solon 2009), but a minimal decline in mobility for 
cohorts born after the 1980s (Mazumder 2012). ${ }^{4}$ Findings by Bloome and Western (2011) and Davis and Mazumder (2020) suggest more heterogeneity in mobility trends for birth cohorts born prior to the 1980s. Davis and Mazumder's (2020) results, for instance, demonstrate that birth cohorts who entered the labor market in the 1980s - a period that coincided with rapid increases in income inequality, among other dimensions of economic inequality - experienced higher intergenerational persistence than birth cohorts who entered the labor market in the 1970s.

As briefly noted in the prior section, Chetty et al. (2014) documented substantial heterogeneity in relative income mobility across and within U.S. regions and states for birth cohorts born in the 1980s. For children of these birth cohorts with parents at the $25^{\text {th }}$ percentile of the national income distribution, the average county-level range of upward mobility in adulthood spans from reaching the $27^{\text {th }}$ income percentile to the $64^{\text {th }}$ income percentile depending on the county labor market one grew up in.

In a similar manner to the theorized association between labor market changes and intergenerational income mobility outcomes made by Davis and Mazumder (2020), noted above, the present study seeks to assess how relative declines in manufacturing employment during the turn of the millennium impacted intergenerational mobility. To accomplish this, I leverage variation in labor market experiences and intergenerational mobility outcomes across birth cohorts and geographic areas.

\section{Life Course Perspectives}

The convergence of life course trajectories with historical events - such as economic downturns, armed conflicts, and pandemics - and the implementation of new policy regimes can

\footnotetext{
${ }^{4}$ In contrast to trends in relative mobility, absolute mobility has declined considerably for birth cohorts born since the 1940s (Chetty et al. 2016; Davis and Mazumder 2020).
} 
impact the life chances of birth cohorts (Almond 2006; Elder 1974; Hout 2015). The experiences of birth cohorts throughout the life course are particularly influenced by the sequential nature of life transitions as well as the idiosyncratic deviations in timing of life transitions for specific cohorts as a result of historical time and place (Elder 1998). Elder's research (e.g. 1998), for instance, demonstrates how the socioeconomic outcomes of cohorts are influenced by the age at which they experience economic adversity. In the Children of the Great Depression, Elder (1974) finds that cohorts in their teenage years during the Great Depression (born in the early 1920s) experienced less economic difficulty in adulthood than cohorts in early adolescence (born in the late 1920s) because they experienced less material deprivation and duress during their formative years of childhood. Variation in age across these two cohorts during the Great Depression also impacted the sequence and timing of life events, including moving away from parental households, marriage, and childbearing.

A broader literature in the social sciences has sought to document how timing of entry into the labor force - whether prior to, during, or after economic recessions - alters the job opportunities, entry salaries, lifetime pay, and educational attainment of cohorts (Atherwood and Sparks 2019; Kahn 2010; Oreopoulos, Wachter, and Heisz 2012; Rinz 2019). Recent findings by Rinz (2019) on the impacts of the Great Recession on employment and earnings finds that younger birth cohorts faced more substantial earnings losses than older birth cohorts. This socalled "failure to launch" initiated by labor market entry during an economic recession can have a cascading set of consequences for life transitions, economic attainment, and autonomy from parents (e.g. Mykyta 2012; Qian 2012).

This literature on economic shocks concentrates primarily on the presence or absence of employment opportunities in local labor markets, but less so on the attributes of those jobs. The 
research conducted here re-conceptualizes economic shocks as fluctuations to the industrial composition of employment opportunities in the manufacturing sector, and the resultant decline in middle-wage, middle-skill jobs. Accordingly, I adjust for the unemployment rate in the statistical analyses to hold constant whether job opportunities are present or not.

I consider two types of measures of compositional change to labor markets: continuous measures of the relative share of employment and annual earnings that are concentrated in the manufacturing sector in a local labor market. Leveraging the alignment of 9 consecutive birth cohorts, I implement a modeling strategy that estimates the relationship between labor market transitions and income mobility through two-way fixed effects. This modeling strategy, described in the next section, allows for an examination of how different experiences of labor market change might set birth cohorts onto very different intergenerational economic attainment paths.

\section{EMPIRICAL APPROACH}

This study takes a macro-level approach towards the analysis of intergenerational mobility processes. The units of analysis are birth cohorts nested within county labor markets. This innovative panel design provides analytical leverage to examine how places produce people over time - how the outcomes of birth cohorts can vary according to annual fluctuations in timevarying economic experiences in their local labor market. By conceptualizing mobility processes as the aggregate outcomes of birth cohorts, rather than the outcomes of individuals, the present analysis emphasizes how opportunity structures are shaped by the combination of geographic and temporal contexts.

A central aim of this study is to examine how labor market conditions upon labor force entry are associated with upward income mobility later in adulthood; therefore, the industrial 
composition of local labor markets are measured at age 18, when most individuals in birth cohorts complete secondary schooling and either enter the labor force immediately or pursue higher education. 5 ,6 The guiding assumptions of selecting this age for when covariates are measured is that (a) manufacturing jobs have historically only required a high school degree, and (b) age 18 is when the majority of individuals in these cohorts entered the labor force (Fernandes-Alcantara 2018; U.S. Bureau of Labor Statistics 2020; author's calculations of BLS data). Critically, this point in the life course coincides with the end of secondary education and the decision to either directly enter the labor force or acquire additional schooling (i.e. vocational training or higher education). As the manufacturing sector has declined in recent decades, the amount of well-paying jobs that only require a high school degree have diminished, and most earnings growth in the sector has occurred for college-educated workers rather than those without a college degree (Levinson 2017). ${ }^{7}$ The intuition of this empirical approach, therefore, is to evaluate how declines in manufacturing employment opportunities in labor markets are associated with reductions in upward mobility.

\section{DATA and METHODS}

To study the relationship between labor market structure and economic opportunity, I combine birth cohort measures of intergenerational income mobility estimated by Chetty et al. (2014) with subnational business register data from the Census Bureau's County Business Patterns (CBP) to estimate county-level associations between manufacturing decline and intergenerational income mobility. I augment this constructed dataset with county- and cohort-

\footnotetext{
5 To assess the sensitivity of age 18 , I additionally estimate models that instead set labor market entry for covariates at age 19 and age 20 .

${ }^{6}$ In a recent study on intergenerational income mobility, Davis and Mazumder (2020) make a similar argument that age of labor market entry is between ages 18-22.

${ }^{7}$ Using data from the CPS, Levinson (2017) shows that there was a $31.5 \%$ decline in workers with high school degrees in the manufacturing sector between 2000 and 2016.
} 
specific social, economic, and compositional covariates to adjust for potential sources of confounding.

\section{Intergenerational Income Mobility}

I access county- and cohort-specific estimates of intergenerational income mobility for birth cohorts between 1980 to 1988 generated by Chetty et al. (2014) using linked parent-child federal tax records (Opportunity Insights 2020). These estimates of intergenerational income mobility comprise nearly $95 \%$ of all U.S. citizens born to each of these nine cohorts. For each birth cohort, Chetty et al. (2014) generated parent income rank by arranging parents according to their mean family income in the national income distribution when the children were between the ages 15-19. Child income rank was generated by arranging children by their family income in the national income distribution at ages 24 and 26. With these two measures of parent and child income from a population-based sample, Chetty et al. (2014) produced measures of "absolute upward mobility" which summarize the mean rank achieved by children at age 24 and 26 conditional on the rank of their parents. The analysis by Chetty et al. (2014) generally indicates a linear relationship for the rank-rank measures of intergenerational income mobility. Therefore, to capture the upward mobility of those at the bottom of the national income distribution, the

present analysis uses a measure of absolute upward mobility conditional on the parents at the $25^{\text {th }}$ income percentile. To capture the overall correlation between parents and children throughout the income distribution, I also use a measure of the rank-rank slope.

Because age 24 and age 26 measures of upward mobility might be influenced by lifecycle bias (discussed in more depth later in this section), I also use mobility measures from Chetty et al. (2018) that consist of estimates of income mobility at ages 31-37 for the aggregated 1978-1983 birth cohorts. These measures from Chetty et al. (2018) come from the same dataset 
of linked parent-child tax records discussed above and were constructed using the same methodology (Opportunity Insights 2020). This aggregate cohort data (in contrast to birth yearspecific cohort data for the age 24 and age 26 measures) helps validate the general across-county results.

\section{Manufacturing Employment}

I operationalize manufacturing as the relative share of jobs in a county labor market that are located in the manufacturing sector. I represent this share in percentage terms to facilitate the interpretation of coefficient tables. To assess the sensitivity of this employment measure, I also use an additional relative measures of manufacturing: the percentage of overall, annual countylevel earnings that are concentrated in the manufacturing sector.

For both operationalizations of manufacturing, I calculate two birth cohort- and countyspecific measures: (1) the percentage of manufacturing at the approximate timing of labor force entry, here defined as age 18, and (2) the percentage point change in manufacturing in a county labor market throughout a birth cohort's adolescent years (i.e. $\Delta M_{c}=M_{c}$, age $0-M_{c}$, age 18, $c=$ county). The first measure is used to test for variation in the availability of manufacturing jobs across county labor markets; the second measure is used to test for the overall decline in manufacturing employment throughout adolescence. The intuition of these two parameters is discussed in further detail in the methods section.

All measures are calculated from full business register data between 1980-2006 accessed from the Census Bureau's County Business Patterns Program (CBP). Prior to 1998, business establishments are classified according to 4-digit Standard Industrial Classification (SIC) codes; starting in 1998 and afterwards, business establishments are classified according to 6-digit North American Industry Classification System (NAICS) codes. Business establishments in 
manufacturing industries are determined based on the 2-digit classification codes 20-39 for SICdesignated years and the 2-digit classification codes 31-33 for NAICS-designated years.

\section{Covariates}

The upward mobility prospects of cohorts might be influenced by a multitude of social, economic, and compositional features of local communities and birth cohorts. The models adjust for several of these important cohort- and labor market-specific contextual features. The covariates included in the present models are specific to the year of labor market entry for each cohort, primarily set at age 18 (e.g. covariates for the 1980 cohort are calculated in 1998; for the 1981 cohort, 1999; etc.).

I use annual county-level population data from the National Center of Health Statistics to calculate the population size and percentage Black population for each cohort at age 18, as well as the percentage of the entire county population who are working-age (15-64). I adjust for several economic characteristics to facilitate identification of the specific influence of manufacturing employment. I access data on county-level poverty rates from the Census Bureau's Small Area Income and Poverty Estimates and county-level unemployment rates from the Census Bureau's Local Area Unemployment Statistics. Data on per capita income are drawn from the Bureau of Economic Analysis and are adjusted to 2000 dollars and logged to adjust for nonnormality. To account for differences in educational attainment across counties over time, I retrieve county-level statistics on the percentage of the population with a high school degree or less from the 1990, 2000, and 2010 Decennial Censuses and use linear interpolation to estimate values for the intercensal years. Finally, since state economic policy regimes and the presence of labor unions are associated with manufacturing decline (Grant and Wallace 1994), I adjust for 
the percentage of workers in each state in each year who are represented by a labor union. ${ }^{8}$ These data are from the Current Population Survey and are calculated and compiled via the Union Membership and Coverage Database (Hirsch and Macpherson 2003).

\section{METHODOLOGY and MODEL SPECIFICATION}

There are two key parameters that are estimated in this analysis: (1) the percentage of manufacturing employment at age of labor force entry (here defined as age 18), and (2) the percentage point change in manufacturing employment between birth and entry into the labor force. The first parameter is important because it quantifies how variation in the relative share of manufacturing jobs across counties might predict income mobility. This parameter also gives an indication about how initial employment opportunities upon labor force entry might set cohorts of workers onto different work trajectories with different economic outcomes. The second parameter is important because it contains information about the history of labor market change in communities, but also the history of labor market change in communities that is specific to each birth cohort. For instance, for the 1980 cohort in county $c$, the change in manufacturing ( $\Delta M_{1980, \mathrm{c}}$ ) would be $\mathrm{M}_{1980, \mathrm{c}}-\mathrm{M}_{1998, \mathrm{c}}$, while the change in manufacturing for the 1981 cohort $\left(\Delta M_{1981, \mathrm{c}}\right)$ would be $\mathrm{M}_{1981, \mathrm{c}-\mathrm{M}_{1999, \mathrm{c}} .}$

Both measures are conceptually distinct and are weakly correlated (for the employment measure, $r=-.13$; for the earnings measure, $r=-.2$ ), indicating that they are measuring different, independent aspects of labor market structure and change.

We might conceptualize the relationship between both parameters as a $2 \times 2$ table (Figure 1A). In this figure, counties that had little manufacturing change over time and little

\footnotetext{
${ }^{8}$ I alternatively test a measure of union membership rather than union coverage which yields approximately the same results.
} 
manufacturing at the year of labor market entry are in cell A; counties with high manufacturing change yet still have high manufacturing are in cell D. Cell B represents counties that maintained robust manufacturing industries over a cohort's adolescence and into the years in which they entered the labor market. Cell C, on the other hand, represents counties that once had strong manufacturing but experienced large declines by the time a cohort had entered the labor force. Each of these cells represent vastly different county-/cohort-specific trajectories and experiences. Simplifying this $2 \times 2$ table to display overall county-level trajectories of manufacturing employment, Figure 1B gives examples for each cell from four Wisconsin counties.

\section{Model Specification}

I estimate pooled birth cohort-county models predicting intergenerational income mobility for birth cohorts born between 1980-1988. The baseline model is estimated as follows:

$$
Y_{b c}=\beta_{1} M_{18, b c}+\beta_{2} \Delta M_{b c}+\beta_{3} x_{b c}+\alpha_{g}+\mu_{b c}
$$

where $Y_{b c}$ refers to the income mobility measure (either the absolute upward mobility for children with parents at the $25^{\text {th }}$ percentile, or the rank-rank slope correlation) for children from birth cohort $b$ and county $c ; \beta_{1} M_{18, b c}$ refers to a coefficient and vector of variables for share of manufacturing at age 18 that is specific to birth cohort $b$ in county $c$ (e.g. for the 1980 cohort, age 18 coincides with the year 1998); $\beta_{2} \Delta M_{b c}$ refers to the percentage point change in the share of manufacturing between birth and entry into the labor force (e.g. for the 1980 cohort, $\Delta M_{\mathrm{bc}}=$ $\left.\mathrm{M}_{1980, \mathrm{c}}-\mathrm{M}_{1998, \mathrm{c}}\right) ; \beta_{3} x_{b c}$ refers to a vector of coefficients and binary coded year variables of yearspecific birth cohorts as well as additional covariates; $\alpha_{g}$ refers to a vector of geography-specific intercepts (set to the commuting zone), and $\mu_{b c}$ refers to birth cohort- and county-specific error terms. To account for non-independence of cohort observations within counties (i.e. nine birth cohorts within each county) and commuting zones, I cluster standard errors at the commuting 
zone level. Moreover, I include a set of population weights when estimating the models - the average cohort size at age 18 for each county.

\section{Life-Cycle Bias}

The data used in this analysis measures children's intergenerational income mobility in early adulthood at ages 24 and 26. Although prior literature on earnings trajectories over the life course suggests that rank-based measures solidify around these ages for cohorts born prior to the 1980s (Chetty, Hendren, Kline, Saez, et al. 2014; Topel and Ward 1992), ${ }^{9}$ it is unknown whether the 1980s cohorts will experience similar patterns of earnings attainment as they continue through the life course. Life-cycle bias - whether point-in-time income is an accurate representation of average lifetime income (Cheng and Song 2019; Haider and Solon 2006) might be an issue for this analysis if (a) earnings trajectories change drastically between the 1980 to 1988 cohorts, and (b) the "head start" for individuals who directly enter the labor force after high school is not surpassed by those who complete a higher education degree and enter the labor market in their early 20 s.

In the latter case, anticipated lifetime earnings for those with a college degree are on average higher than those with only a high school degree; but a measure of intergenerational income mobility will not represent this average lifetime rank distribution if it is measured when those with a college degree are only beginning their careers and have lower job tenure and earnings attainment than those without a college degree who have had more time for career advancement. Moreover, life-cycle bias can also result from the inconsistency between point-intime versus lifetime measurement of the parent's income. Since the current analysis compares 9

\footnotetext{
${ }^{9}$ Topel and Ward (1992) estimate that approximately 2/3rds of lifetime wage growth for individuals occurs during their first decade in the labor market.
} 
successive birth cohorts, life-cycle bias on the parents' side of the rank-rank measurement should not be an issue when comparing across birth cohorts because the average parents age for these cohorts did not change substantially over this time period (Appendix Figure 1).

I address the broader issue of life-cycle bias by estimating a separate set of models using data from Chetty et al. (2018) that measures income mobility over a longer period of time, at ages 31-37 for the combined 1978-1983 cohorts. These models, presented in the results section, indicate that the same pooled estimates hold when estimated at a later point in the life course, which provide evidence that life-cycle bias is not driving the results.

\section{The Impact of Manufacturing Decline on Parents Income}

Deindustrialization has not only impacted the occupational opportunities of new entrants into the labor force, but also the opportunities of mid- and late-career workers as well. The parents of the children from the 1980-1988 birth cohorts might also experience job displacement and/or income loss as the result of the changing industrial structure of U.S. labor markets. The extent to which this is the case will downwardly bias the estimates of upward income mobility (as well as the coefficient estimates in the models) because parents' rank will be lower as the result of deindustrialization-induced income loss. The data used in this study do not provide the ability to address this methodological concern directly, but it does allow for insight into the extent to which this is an issue.

Figure 2 presents a heat map of the share of employment in manufacturing industries by binned age groups (on the y-axis) and year (on x-axis), using data from the Census Bureau's Quarterly Workforce Indicators dataset (QWI). This figure illustrates that between the 19982006 period, the rate of change in manufacturing employment decreased more rapidly for younger workers than older workers. The decline in manufacturing employment for those in the 
35-44 and 45-54 age groups decreased much more gradually than those in the late teens and 20s age groups. This graphical representation of manufacturing decline demonstrates that for the 1998-2006 period, we should expect the association to be driven by manufacturing employment decline for the children and not the parents. I formally test whether this is the case by running a set of sensitivity models that separately swap out the overall manufacturing employment parameter for age group-specific manufacturing employment parameters. The results provide evidence that the decline of manufacturing employment for older age workers is not overly influencing the findings of the main analysis.

\section{RESULTS}

Descriptives

Table 1 displays key descriptive statistics for the entire sample. The average share of county-level manufacturing employment during labor market entry (i.e. 1998-2006) for the 1980-1988 cohorts was $14.5 \%$ ( $\mathrm{SD}=9.6$ ). From birth until labor force entry at age 18 , these cohorts witnessed an average 10.2 ( $\mathrm{SD}=7.9)$ percentage point decline in county-level manufacturing employment.

To provide broader context on the decline of the U.S. manufacturing sector, Figure 3 displays the changing distribution of the percentage of jobs in manufacturing between 19752016. The average county share of manufacturing employment in 1980 was $28 \%$; in 1990 , $23.5 \%$; in $2000,20.1 \%$; and in $2016,16.3 \%$. Over this nearly four-decade period, the distribution of manufacturing employment becomes increasingly positively skewed, demonstrating the large extent to which county-level labor markets have experienced declines in manufacturing employment. 
Figure 4 maps the percentage of manufacturing employment at age 18 for the 1980 birth cohort (labor force entry in 1998) and the 1988 birth cohort (labor force entry in 2006). The Midwest and Southeast regions had the highest levels of manufacturing employment in the nation compared to other regions; although these regions also experienced noticeable declines in manufacturing employment between 1998 and 2006. Figure 5 maps the percentage point decline in manufacturing employment between birth and labor market entry for the 1980 and the 1988 birth cohorts. The diverging color palette in this figure accentuates regions that experienced net increases or decreases in manufacturing employment. Values for this measure are calculated as the difference between county-level manufacturing employment at age 0 and age 18; accordingly, positive values signify cohorts that witnessed net declines in county-level manufacturing employment throughout their adolescence. Counties in the Southeast, Great Lakes area of the Midwest, Northeast, and Northwest all experienced reductions in manufacturing employment over this period. In contrast, the West North Central area of the Midwest and the Intermountain region experienced slight increases in manufacturing employment, which corresponds with previously documented regional trends of manufacturing growth throughout the 1980s and 1990s (e.g. Helper et al. 2012).

\section{Variation across Labor Markets}

Table 2 displays the coefficients for models estimating rank in the national household income distribution for those from the $25^{\text {th }}$ income percentile as well the rank-rank slope at age 24 (Panel A), age 26 (Panel B), and ages 31-37 (Panel C). All models presented in this table include commuting zone fixed effects which adjust for unobserved time-varying social, economic, and contextual characteristics shared by counties within the same local labor market, even for those that span state borders. This level of fixed effects is a more robust adjustment than 
state fixed effects, although state-level economic policies and other public policies might be as salient in shaping opportunity structures (e.g. Montez, Hayward, \& Zajacova 2019).

I operationalize the industrial composition of labor markets as (a) the share of jobs in a labor market located within the manufacturing sector upon labor force entry, expressed as a percentage, and (b) the percentage point change in the share of manufacturing employment between birth and labor force entry. ${ }^{10}$ Although employment is the clearest indicator of occupational opportunities in the manufacturing sector, I assess the sensitivity of this measure with an additional operationalization: the percentage of total annual labor market earnings that are taken home by manufacturing workers.

The first two columns in the table present models that predict the number of income percentile ranks a child can expect to climb conditional on having a parent at the $25^{\text {th }}$ income percentile. For the models using manufacturing employment, the results indicate that a one percentage point increment in manufacturing employment in a county labor market is associated with a significant $.088($ S.E. $=.016)$ increase in national household income rank at age 24 (Panel A) and a significant $.071($ S.E. $=.015)$ increase in national household income rank at age 26 (Panel B). For the change in manufacturing employment between birth and labor force entry coefficient, a one percentage point decline in manufacturing employment between birth and labor market entry is associated with a significant -.057 (S.E. $=.013)$ decrease in national household income rank at age 24 (Panel A) and a significant -.054 (S.E. = .012) decrease in national household income rank at age 26 (Panel B).

\footnotetext{
${ }^{10}$ The models in the main analysis use age 18 as the modal year of labor market entry. I assess the sensitivity of this assumption through supplementary models that instead set labor market entry for manufacturing measures and covariates to age 19 and age 20. A summary of the results, presented in Appendix Table 1, demonstrate how the coefficient estimates are insensitive to the modeling choice of whether to set labor market entry as age 18,19 , or 20 .
} 
The final two columns in the table present models that predict the rank-rank slope measure of intergenerational income mobility. The results provide a similar story as to the absolute upward mobility measure: a one percentage point increment in manufacturing employment upon labor force entry is associated with a significant decrease in the parent-child income rank correlation of $-.074($ S.E. $=.028)$ at age 24 and $-.071($ S.E. $=.028)$ at age 26. An additional one percentage point decrease in manufacturing employment between birth and labor force entry is associated with a significant increase in the rank-rank slope of $.08($ S.E. $=.026)$ at age 24 and $.091($ S.E. $=.025)$ at age 26. These results indicate that fewer employment opportunities in the manufacturing sector upon labor market entry and a greater decrease in employment opportunities over time are both associated with a stronger correlation between parent and child income ranks.

Using the additional operationalization of the manufacturing composition of labor markets, annual earnings, the results are approximately the same, with mostly equivalent effect sizes and precision of estimates for both the age 24 and age 26 income mobility outcomes.

To account for the possibility of life-cycle bias - that is, to determine whether age 24 and age 26 are too early in the life course to accurately evaluate average lifetime rank distributions in income - I present models estimating rank in the national household income distribution at ages 31-37 in Panel C. Although mobility data are only available here for the aggregate 1978-1983 cohort, the estimates are similar, albeit smaller in magnitude, than those that include separate observations for the 9 cohorts in Panels A and B. ${ }^{11}$ Overall, the results from these later-life

\footnotetext{
${ }^{11}$ Note, however, that the variable distributions for the manufacturing and mobility measures are different for the models in this final panel since they are based on aggregate values of the 1978-1983 cohorts. The effect size is not directly comparable to the models in the previous two panels.
} 
mobility estimate models provide evidence that life-cycle bias should not be an excessive concern when interpreting the age 24 and age 26 models.

Overall, what do the results from this table mean? For the percentage manufacturing employment parameter at age 26 (absolute upward mobility), the difference between counties at the $10^{\text {th }}$ percentile $\left(5.4 \%\right.$ of employment in manufacturing) and $90^{\text {th }}$ percentile $(27.1 \%$ of employment in manufacturing) of the distribution is roughly equivalent to a difference of 1.5 income rank percentiles at age 26 . Between the $1^{\text {st }}$ percentile ( $2 \%$ of employment in manufacturing) and the $99^{\text {th }}$ percentile (48.3\% of employment in manufacturing) of the distribution, this is equivalent to a 3.1 percentile difference in income mobility.

In terms of the change in manufacturing employment $(\Delta M)$ parameter, county-cohorts experienced an average decline of 10.5 percentage points in manufacturing employment between birth and labor market entry, which indicates that the average decline in intergenerational mobility associated with declines in manufacturing employment is about 0.55 income percentiles. At the $99^{\text {th }}$ percentile (28.9 percentage point loss in manufacturing), $\Delta M$ predicts a decline of 1.5 income percentiles. These results demonstrate how year of birth matters not just in terms of the opportunities that are available upon labor market entry 18 years later, but also in terms of the shifting 18-year window of history for which each cohort lives through.

\section{Manufacturing Decline by Age Group}

An important assumption of the previously estimated equations is that the structural declines in manufacturing employment are primarily impacting the economic opportunities of the children from these birth cohorts rather than their parents. If the parents of these birth cohorts are experiencing job displacement from the manufacturing sector, and consequently, experiencing substantial reductions in household income, then the estimates from Eq. 1 will be 
biased downwards. That is, the parents' income, measured when the birth cohort is ages 15-19, might be impacted by the same process that is constraining the income attainment of the children. I evaluate whether this concern of endogeneity is substantially biasing the results by estimating separate models that use county-level age group specific measures of manufacturing employment to predict upward income mobility. These data are drawn from the Census Bureau's Quarterly Workforce Indicators database and the age groups vary in bin size across the age distribution (e.g. 14-18, 19-21, 22-24, 25-34). If the theoretical model posited throughout this study is correct, then we should expect that the effect size should be largest at the younger end of the age distribution. After all, the decline of manufacturing employment opportunities for new entrants into the labor force is what should be most predictive of reductions in income mobility for these birth cohorts. Conversely, a uniform effect size across the age distribution might suggest that the previous models are underestimating the true effect size, since manufacturing decline for those in mid-life, for instance, would be as predictive of changes in intergenerational mobility as manufacturing decline for the 1980s birth cohorts studied in this analysis.

Figure 6 presents the summary results of these models for both the absolute upward mobility and rank-rank slope measures for mobility at ages 24 and 26. I estimate these models using the model specifications used in the prior analyses, adjusting for the $\Delta \mathrm{M}$ parameter with overall county-level manufacturing because data on age group specific measures from the QWI dataset are only available starting from 1990. For this set of models, I set labor market entry age at 19 - i.e. all covariates are measured for each cohort when they are age 19 - because the QWI data age-group that most aligns with labor market entry is the 19-21 age category.

The results show that the magnitude of the manufacturing employment coefficient is highest at the younger end of the age distribution. For all models, there is generally a monotonic 
decrease in effect size and significance level as the coefficient estimated goes up the age distribution. This suggests that older age manufacturing employment levels do not predict intergenerational income mobility for the 1980-1988 birth cohorts as strongly as younger age manufacturing employment levels. For the ages 19-21 coefficient in Panel C, a one percentage point increment in manufacturing employment is associated with a .137 increase in rank in upward mobility at age 26 in the national household income distribution, which is equivalent to a difference between the $10^{\text {th }}$ percentile (2.7\% of $19-21$ year old's in manufacturing) and $90^{\text {th }}$ percentile (26.6\% of 19-21 year old's in manufacturing) of about 3.3 income percentile ranks. Across the $1^{\text {st }}$ percentile $(1.9 \%)$ and $99^{\text {th }}$ percentile $(49.6 \%)$, this represents a difference in upward movement of 6.5 income percentile ranks. The findings from this analysis therefore suggest that (a) the potential endogeneity between manufacturing and income should not be impacting the estimation of the previous models too much, but also, (b) the magnitude of the effect size of declining manufacturing on upward mobility for the 1980-1988 birth cohorts is even larger when swapping out the overall county measure of manufacturing for the ages 19-21 measure of manufacturing.

\section{DISCUSSION}

The aim of this study was to examine whether the changing industrial composition of U.S. labor markets - and consequently, the availability of middle wage job opportunities - has suppressed upward intergenerational mobility. I constructed a detailed county-level dataset that consisted of cohort-varying measures of labor market characteristics and intergenerational income mobility. The unique panel structure and modeling strategy of this analysis demonstrates the analytical utility of conceptualizing how variation across and within ecological contexts can produce disparities in economic attainment across generations. Rather than examining 
individual-level work histories on intergenerational mobility, the present study contributes to the literature on stratification processes by giving precedence to the compositional role of labor markets on aggregate population processes. As deindustrialization transforms the nature of work in the U.S. and globally, this macro-level approach clarifies the population-level consequences. The findings illustrate how the geography of economic mobility is appreciably determined by ecological features of local labor markets.

The results provide two new important findings and contributions to the literature on social stratification and life course trajectories. First, for birth cohorts born between 1980-1988, entering a labor market with a high relative share of manufacturing jobs was associated with increased upward income mobility in adulthood in comparison to entering a labor market with fewer manufacturing jobs. This finding is perhaps the most robust association estimated in this study, showing durability regardless of whether the child's income attainment was measured at ages 24,26 , or 31-37, and irrespective of birth cohort. For the age 26 measure, for instance, the difference between being raised in the bottom $1^{\text {st }}$ percentile and top $99^{\text {th }}$ percentile of areas with overall manufacturing employment translates into a gap of 3.1 income percentile ranks of upward mobility. Doing the same comparison with instead an age-specific measure of manufacturing employment for new entrants into the labor market yields a difference of 6.5 income percentile ranks of upward mobility.

The second primary finding of this study is that industrial composition does not only matter in terms of the immediate availability of job opportunities, but also in terms of how industrial change has impacted communities over time. The social and economic contexts of communities can change drastically over time; the opportunities that parents expect will be available to their children upon adulthood can dissipate by the time the children's birth cohort 
enters the labor force almost two decades after birth. As demonstrated in this analysis, the amount and pace of labor market change varies considerably across U.S. counties. How might this industrial change manifest itself and contribute to reductions in upward mobility? Possibilities might include deterioration of the built environment (e.g. idled or shuttered factories) as a reminder of vanished opportunity and perceived opportunity (Goldstein 2017), economic "despair" initiated by the lack of economic opportunities (Case and Deaton 2017; Shanahan et al. 2019), and demographic changes such as economic out-migration and shifting age distributions. The findings emphasize the importance of this change over time: larger longterm losses in relative manufacturing employment were associated with reduced upward mobility. Long-term manufacturing decline was associated with an average reduction of half of an income percentile in upward movement in the national income rank distribution, with areas that experienced the sharpest reductions in manufacturing employment experiencing a reduction of 1.5 income rank percentiles in upward mobility.

\section{Limitations}

An important limitation of this analysis is that the manufacturing and mobility measures are aggregate and ecological, which means that the models estimated here should only be used to describe macro-level cohort and county processes. Yet, this macro-level approach is informative because it charts out meaningful variation in opportunity structures across birth cohorts and geographic areas. Rather than a constraint, this population-level emphasis provides novel insight into how ecological economic contexts can shape social mobility across generations. That said, readers should take caution when using this research to describe individual-level social mobility. While I attempt to address several issues that might bias the results of aggregate analysis, I cannot fully account for variation across individuals. Future research should link data on 
individual-level work histories with contextual, community-specific labor market characteristics to evaluate how structural economic changes have impacted upward economic mobility.

As noted throughout this study, two other important concerns/limitations of this analysis include (a) life-cycle bias and (b) the impacts of deindustrialization on parental income rank. Through robustness models that swapped out the age 24 and age 26 measures of income mobility for ages 31-37 measures of income mobility, the results generally remained the same; this suggests that life-cycle bias should not be overly influencing the findings, although the effect size does diminish slightly as these cohorts age. This might suggest that birth cohorts were able, to some extent, surmount the economic penalties they initially faced from declining opportunities in their local labor markets. Regardless if life-cycle bias were a larger concern, the results would still demonstrate how early adult trajectories of income rank are impacted by changes to the industrial composition of labor markets.

I address the potential endogeneity issue of manufacturing decline biasing the estimates of upward intergenerational mobility by estimating a set of separate models that swap out overall county- and cohort-/year-specific measures of manufacturing employment for age group-, county-, and cohort-/year-specific measures of manufacturing employment. These sensitivity models document a larger and more highly significant relationship between manufacturing employment and intergenerational mobility at the younger end of the age distribution. This implies that the main models are not unduly impacted by this endogeneity concern; yet, the data and modeling strategy are unable to entirely quantify the extent to which this might downwardly bias the estimates. 


\section{CONCLUSIONS}

In short, the results suggest two new important findings and contributions. First, children from the 1980-1988 cohorts who lived in counties with a higher share of manufacturing operationalized as either employment or annual payroll - experienced increased income mobility outcomes in comparison to those who lived in counties with a lower share of manufacturing.

Second, children from these cohorts who lived in counties that experienced larger contractions in manufacturing throughout their adolescence faced larger economic penalties in adulthood via reduced levels of upward intergenerational mobility. This research therefore charts a new direction in the literature on social stratification being the first study to directly examine how variation in the loss of manufacturing jobs across labor markets has contributed to growing disparities in upward mobility across geographic areas and birth cohorts. 


\section{REFERENCES}

Acemoglu, Daron, and David Autor. 2011. "Skills, Tasks and Technologies: Implications for Employment and Earnings.” Pp. 1043-1171 in Handbook of Labor Economics. Vol. 4b.

Almond, Douglas. 2006. "Is the 1918 Influenza Pandemic Over? Long- Term Effects of In Utero Influenza Exposure in the Post-1940 U.S. Population." Journal of Political Economy 114(4):672-712.

Atherwood, Serge, and Corey S. Sparks. 2019. "Early-Career Trajectories of Young Workers in the U.S . in the Context of the 2008 - 09 Recession: The Effect of Labor Market Entry Timing." PLoS ONE 14(3):1-30.

Atkinson, Robert D., Luke A. Stewart, Scott M. Andes, and Stephen J. Ezell. 2012. Worse than the Great Depression: What Experts Are Missing About American Manufacturing Decline.

Autor, David H., and David Dorn. 2013. "The Growth of Low-Skill Service Jobs and the Polarization of the US Labor Market." American Economic Review 103(5):1553-97. doi: 10.1257/aer.103.5.1553.

Autor, David H., Lawrence F. Katz, and Melissa S. Kearney. 2006. "The Polarization of the U.S. Labor Market.” American Economic Review 96(2):189-94. doi: 10.1257/000282806777212620.

Black, Sandra E., and Paul J. Devereux. 2010. Recent Developments in Intergenerational Mobility. Cambridge, MA.

Bloome, Deirdre, and Shauna Dyer. 2018. "Educational Inequality , Educational Expansion , and Intergenerational Income Persistence in the United States." American Sociological Review 83(6):1215-53. doi: 10.1177/0003122418809374.

Bloome, Deirdre, and Bruce Western. 2011. "Cohort Change and Racial Differences in Educational and Income Mobility.” Social Forces 90(2):375-95.

Bureau of Labor Statistics, U. S. Department of Labor. 2020. "Union Membership Rate 8.6 Percent in Manufacturing, 23.4 Percent in Utilities, in 2019." The Economics Daily.

Carrington, William J., and Bruce C. Fallick. 2015. Do We Know Why Earnings Fall with Job Displacement? Do We Know Why Earnings Fall with Job Displacement? Washington, D.C.

Case, Anne, and Angus Deaton. 2015. "Rising Morbidity and Mortality in Midlife among White Non-Hispanic Americans in the 21st Century." Proceedings of the National Academy of Sciences 112(49):15078-83. doi: 10.1073/pnas.1518393112.

Case, Anne, and Angus Deaton. 2017. "Mortality and Morbidity in the 21st Century." Brookings Papers on Economic Activity 397-476. doi: 10.1073/pnas. 1518393112.

Case, Anne, and Angus Deaton. 2020. Deaths of Despair and the Future of Capitalism. Princeton \& Oxford: Princeton University Press.

Cha, Youngjoo, and Stephen L. Morgan. 2010. "Structural Earnings Losses and BetweenIndustry Mobility of Displaced Workers, 2003 - 2008." Social Science Research 39(6):1137-52. doi: 10.1016/j.ssresearch.2010.08.002. 
Charles, Kerwin Kofi, Erik Hurst, and Matthew J. Notowidigdo. 2018. "Housing Booms, Manufacturing Decline and Labour Market Outcomes.” The Economic Journal 55(2012):150. doi: 10.1111/ecoj.12598.

Cheng, Siwei, and Xi Song. 2019. "Linked Lives, Linked Trajectories: Intergenerational Association of Intragenerational Income Mobility." American Sociological Review 84(6):1037-68. doi: 10.1177/0003122419884497.

Chetty, Raj, David Grusky, Maximilian Hell, Nathaniel Hendren, Robert Manduca, and Jimmy Narang. 2016. The Fading American Dream: Trends in Absolute Income Mobility Since 1940. Cambridge, MA.

Chetty, Raj, Nathaniel Hendren, Patrick Kline, and Emmanuel Saez. 2014. "Where Is the Land of Opportunity? The Geography of Intergenerational Mobility in the United States." Quarterly Journal of Economics 129(4):1553-1623. doi: 10.1093/qje/qju022.Advance.

Chetty, Raj, Nathaniel Hendren, Patrick Kline, Emmanuel Saez, and Nicholas Turner. 2014. "Is the United States Still a Land of Opportunity? Recent Trends in Intergenerational Mobility." American Economic Review: Papers \& Proceedings 2014, 104(5):141-47.

Couch, Kenneth A., Gayle L. Reznik, Howard M. Iams, and Christopher R. Tamborini. 2018. "The Incidence and Consequences of Private Sector Job Loss in the Great Recession." Social Security Bulletin 78(1):31-46.

Curtis, Katherine J., Junho Lee, Heather A. O’Connell, and Jun Zhu. 2019. “The Spatial Distribution of Poverty and the Long Reach of the Industrial Makeup of Places: New Evidence on Spatial and Temporal Regimes.” Rural Sociology 84(May 2018):28-65. doi: 10.1111/ruso.12216.

Davis, Jonathan M. V, and Bhashkar Mazumder. 2020. The Decline in Intergenerational Mobility After 1980.

Eckert, Fabian, Teresa C. Fort, Peter K. Schott, and Natalie J. Yang. 2020. Imputing Missing Values in the US Census Bureau's County Business Patterns.

Elder, Glen H. 1974. Children of the Great Depression: Social Change in Life Experience. 1st Editio. Chicago, IL: University of Chicago Press.

Elder, Glen H. 1998. "The Life Course as Developmental Theory.” Child Development 69(1):112.

Fallick, Bruce C. 1996. "A Review of the Recent Empirical Literature on Displaced Workers." Industrial and Labor Relations Review 50(1):5-15.

Fernandes-Alcantara, Adrienne L. 2018. Youth and the Labor Force: Background and Trends.

Goldstein, Amy. 2017. Janesville: An American Story. New York: Simon \& Schuster.

Grant, Don Sherman I. I., and Michael Wallace. 1994. "The Political Economy of Manufacturing Growth and Decline across the American States, 1970-1985." Social Forces 73(1):33-63.

Green, Gary Paul, and Landy Sanchez. 2007. “Does Manufacturing Still Matter?” Population Research and Policy Review 26(5-6):529-51. doi: 10.1007/s11113-007-9043-8.

Greenland, Andrew, John Lopresti, and Peter Mchenry. 2019. "Import Competition and Internal Migration." The Review of Economics and Statistics 101(March):44-59. doi: 10.1162/rest. 
Haider, Steven, and Gary Solon. 2006. "Life-Cycle Variation in the Association between Current and Lifetime Earnings." American Economic Review 96(4):1308-20.

Helper, Susan, Timothy Krueger, and Howard Wial. 2012. Locating American Manufacturing: Trends in the Geography of Production.

Hirsch, Barry T., and David A. Macpherson. 2003. "Union Membership and Coverage Database from the Current Population Survey: Note." Industrial and Labor Relations Review 56(2):349-54.

Hochschild, Arlie R. 2017. Strangers in Their Own Land: Anger and Mourning on the American Right. New York: The New Press.

Hollister, Matissa. 2011. "Employment Stability in the U . S . Labor Market : Rhetoric versus Reality." doi: 10.1146/annurev-soc-081309-150042.

Hout, Michael. 2015. "A Summary of What We Know about Social Mobility." The ANNALS of the American Academy of Political and Social Science (January):27-36. doi: $10.1177 / 0002716214547174$.

Jacobs, Ken, Zohar Perla, Ian Perry, and Dave Graham-squire. 2016. Producing Poverty: The Public Cost of Low-Wage Production Jobs in Manufacturing.

Janoski, Thomas, David Luke, and Christopher Oliver. 2014. The Causes of Structural Unemployment : Four Factors That Keep People from the Jobs They Deserve. Polity Press.

Jarvis, Benjamin F., and Song, Xi. 2017. "Rising Intragenerational Occupational Mobility in the United States, 1969 to 2011." American Sociological Review 82(3):568-99.

Kahn, Lisa B. 2010. "The Long-Term Labor Market Consequences of Graduating from College in a Bad Economy." Labour Economics 17(2):303-16.

Kalleberg, Arne L. 2009. "Precarious Work, Insecure Workers: Employment Relations in Transition.” American Sociological Review 74(1):1-22.

Kalleberg, Arne L. 2018. Precarious Lives: Job Insecurity and Well-Being in Rich Democracies. Wiley.

Lee, Chul-in, and Gary Solon. 2009. "Trends in Intergenerational Income Mobility." 91(November):766-72.

Levinson, Marc. 2017. Job Creation in the Manufacturing Revival Job Creation in the Manufacturing Revival. Washington, D.C.

Mazumder, Bhashkar. 2012. "Is Intergenerational Economic Mobility Lower Now than in the Past?" Chicago Fed Letter (297).

Monnat, Shannon M. 2019. "The Contributions of Socioeconomic and Opioid Supply Factors to U.S. Drug Mortality Rates: Urban-Rural and within-Rural Differences.” Journal of Rural Studies 68(December 2018):319-35. doi: 10.1016/j.jrurstud.2018.12.004.

Moretti, Enrico. 2012. The New Geography of Jobs. Houghton Mifflin Harcourt.

Mykyta, Laryssa. 2012. "Economic Downturns and the Failure to Launch: The Living Arrangements of Young Adults in the U.S. 1995-2011." U.S Census Bureau 1-37.

Opportunity Insights. 2020. “Opportunity Insights, Data.” Retrieved 
(https://opportunityinsights.org/).

Oreopoulos, Philip, Till Von Wachter, and Andrew Heisz. 2012. "The Short- and Long-Term Career Effects of Graduating in a Recession." American Economic Journal: Applied Economics 4(1):1-29.

Packer, George. 2013. The Unwinding: An Inner History of the New America. New York: Farrar, Straus and Giroux.

Parrado, Eric, Caner Asena, and Edward N. Wolff. 2007. "Occupational and Industrial Mobility in the United States." Labour Economics 14(3):435-55.

Qian, Zhenchao. 2012. "During the Great Recession, More Young Adults Lived with Parents."

Rinz, Kevin. 2019. Did Timing Matter? Life Cycle Differences in Effects of Exposure to the Great Recession. Washington, D.C.

Schneider, Daniel, and Kristen Harknett. 2019. "Consequences of Routine Work-Schedule Instability for Worker Health and Well-Being." American Sociological Review 84(1):82114. doi: $10.1177 / 0003122418823184$.

Seltzer, Nathan. 2019. "Beyond the Great Recession: Labor Market Polarization and Ongoing Fertility Decline in the United States." Demography. doi: 10.1007/s13524-019-00790-6.

Shanahan, Lilly, Sherika N. Hill, Lauren M. Gaydosh, Annekatrin Steinhoff, E. Jane Costello, Kenneth A. Dodge, Kathleen Mullan Harris, and William E. Copeland. 2019. "Does Despair Really Kill ? A Roadmap for an Evidence-Based Answer." American Journal of Public Health 109(6):854-58. doi: 10.2105/AJPH.2019.305016.

Tolbert, Charles M., and Molly Sizer. 1996. U.S. Commuting Zones and Labor Market Areas: A 1990 Update.

Topel, Robert H., and Michael P. Ward. 1992. "Job Mobility and the Careers of Young Men." The Quarterly Journal of Economics 107(2):439-79.

U.S. Bureau of Labor Statistics. 2020. "Labor Force Participation Rate - 18-19 Yrs. [LNS11300088]."

Venkataramani, Atheendar S., Elizabeth F. Bair, Rourke L. O'Brien, and Alexander C. Tsai. 2020. "Association Between Automotive Assembly Plant Closures and Opioid Overdose Mortality in the United States A Difference-in-Differences Analysis." JAMA Internal Medicine 19104:1-9. doi: 10.1001/jamainternmed.2019.5686.

Winkler, Richelle, Kenneth M. Johnson, Cheng Cheng, Jim Beaudoin, Paul R. Voss, and Katherine J. Curtis. 2013. “Age-Specific Net Migration Estimates for US Counties, 19502010.” 


\section{TABLES}

Table 1. Key Descriptive Statistics

\begin{tabular}{lll}
\hline Measure & Mean & Std. Dev. \\
\hline Absolute Upward Mobility (Household Income Distribution) & & \\
25 $5^{\text {th }}$ percentile origin at age 24 & 46 & 4.4 \\
$25^{\text {th }}$ percentile origin at age 26 & 44.3 & 4.4 \\
25 $5^{\text {th }}$ percentile origin at age 31-37 & 41.3 & 4.2 \\
Employment & & \\
\% Manufacturing & 14.4 & 9.6 \\
$\Delta$ Manufacturing & 10.2 & 7.9 \\
Annual Payroll & & \\
\% Manufacturing & 18.3 & 12.7 \\
$\Delta$ Manufacturing & 12.0 & 10 \\
Manufacturing Employment by Age Category ${ }^{1}$ & & \\
All Ages & 12.7 & 8.1 \\
14-18 & 3.5 & 2.8 \\
19-21 & 7 & 6.4 \\
22-24 & 9.3 & 7.8 \\
25-34 & 12.3 & 8.9 \\
35-44 & 14.5 & 9.2 \\
$45-54$ & 14.7 & 9 \\
55-64 & 14 & 8.5 \\
\hline
\end{tabular}

Notes: ${ }^{1}$ Data from the Quarterly Workforce Indicators Dataset. 
Table 2. Parameter Estimates of Manufacturing Measures from Commuting Zone Fixed Effects Models Predicting Intergenerational Income Mobility at Age 24 (Panel A) and Age 26 (Panel B) for 1980-1988 Cohorts, and Age 31-37 (Panel C) for 1978-1983 Cohorts

\begin{tabular}{lll|ll}
\hline A. Age 24 & \multicolumn{2}{c}{ Absolute Upward Mobility } & \multicolumn{2}{c}{ Rank-Rank Slope } \\
\cline { 2 - 4 } & Employment & Annual Payroll & Employment & Annual Payroll \\
\hline \% Manufacturing & $0.088^{* * *}$ & $0.052^{* * *}$ & $-0.074^{* *}$ & -0.037 \\
& $(0.016)$ & $(0.011)$ & $(0.028)$ & $(0.019)$ \\
$\Delta$ Manufacturing & $-0.057^{* * *}$ & $-0.044^{* * *}$ & $0.080^{* *}$ & $0.072^{* * *}$ \\
(cohort: age 0-18) & $(0.013)$ & $(0.009)$ & $(0.026)$ & $(0.018)$ \\
\hline Observations & 11666 & 11666 & 11666 & 11666 \\
R2 & 0.785 & 0.784 & 0.674 & 0.674 \\
\hline
\end{tabular}

\begin{tabular}{lll|ll}
\hline B. Age 26 & \multicolumn{2}{c}{ Absolute Upward Mobility } & \multicolumn{2}{c}{ Rank-Rank Slope } \\
& Employment & Annual Payroll & Employment & Annual Payroll \\
\hline \% Manufacturing & $0.071^{* * *}$ & $0.038^{* * *}$ & $-0.071^{* *}$ & -0.036 \\
& $(0.015)$ & $(0.011)$ & $(0.028)$ & $(0.020)$ \\
$\Delta$ Manufacturing & $-0.054^{* * *}$ & $-0.044^{* * *}$ & $0.091^{* * *}$ & $0.089^{* * * *}$ \\
(cohort: age 0-18) & $(0.012)$ & $(0.009)$ & $(0.025)$ & $(0.017)$ \\
\hline Observations & 9179 & 9179 & 9179 & 9179 \\
R2 & 0.804 & 0.803 & 0.728 & 0.729 \\
\hline
\end{tabular}

C. Age 31-37

\begin{tabular}{lll|ll}
\hline & \multicolumn{2}{c|}{ Absolute Upward Mobility } & \multicolumn{2}{c}{ Rank-Rank Slope } \\
& Employment & Annual Payroll & Employment & Annual Payroll \\
\hline \% Manufacturing & $0.030^{*}$ & 0.011 & -0.018 & -0.007 \\
& $(0.013)$ & $(0.010)$ & $(0.023)$ & $(0.017)$ \\
A Manufacturing & $-0.034^{* *}$ & $-0.035^{* * *}$ & $0.053^{* *}$ & $0.061^{* * *}$ \\
(cohort: age 0-18) & $(0.011)$ & $(0.008)$ & $(0.018)$ & $(0.013)$ \\
\hline Observations & 2642 & 2642 & 2642 & 2642 \\
R2 & 0.878 & 0.878 & 0.792 & 0.794 \\
\hline
\end{tabular}

$* \mathrm{p}<.05, * * \mathrm{p}<.01, * * * \mathrm{p}<.001$ (two tailed tests)

Notes: (a) Age 24 (Panel A) and age 26 (Panel B) models include 9 separate cohorts born between 1980-1988 nested within each county; Age 31-37 (Panel C) models include only an aggregate1978-1983 cohort; (b) Models are weighted by average within-county cohort size at age 18; (c) Standard errors clustered at the commuting zone level; (d) covariates include birth cohort FE (for the age 24 and age 26 models), cohort population at age 18, \% of cohort black, county poverty rate, county logged per capita income adjusted to year 2000 dollars, county unemployment rate, county-level $\%$ with high school or less educational attainment, state-level $\%$ of workers represented by labor unions, and county $\%$ working age population and \% old age dependent population; (e) All covariates are timevarying for when cohort is age 18 . 


\section{FIGURES}

Figure 1A. Conceptual 2x2 Table of Level of Manufacturing Employment Parameter (\%M) and Change in Manufacturing Employment Between Birth and Labor Force Entry Parameter $(\Delta \mathrm{M})$

\begin{tabular}{|c|c|c|}
\hline & $\begin{array}{c}\text { Low } \\
\% \mathrm{M}\end{array}$ & $\begin{array}{c}\text { High } \\
\% \mathrm{M}\end{array}$ \\
\hline $\begin{array}{r}\text { Low } \\
\Delta \mathrm{M}\end{array}$ & $\mathrm{A}$ & $\mathrm{B}$ \\
\hline $\begin{array}{c}\text { High } \\
\Delta \mathrm{M}\end{array}$ & $\mathrm{C}$ & $\mathrm{D}$ \\
\hline
\end{tabular}

Figure 1B. Examples of Each Cell from Conceptual 2x2 Table Using Data from Wisconsin Counties
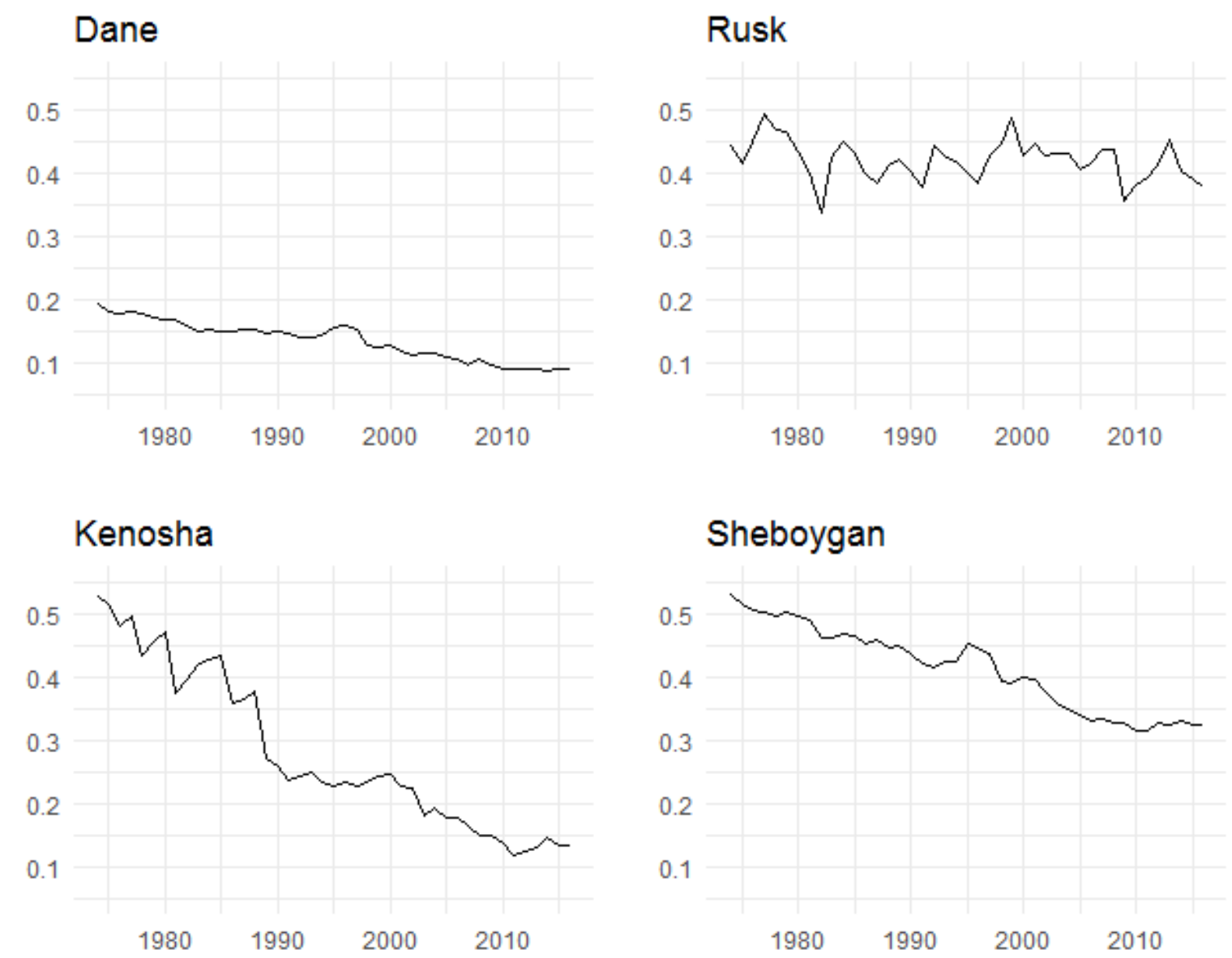

Notes: (a) y-axis indicates share of employment in county in manufacturing industries; $\mathrm{x}$-axis indicates calendar year. 
Figure 2. Heat Map of the Average Share of Manufacturing Employment by Age Group and Year

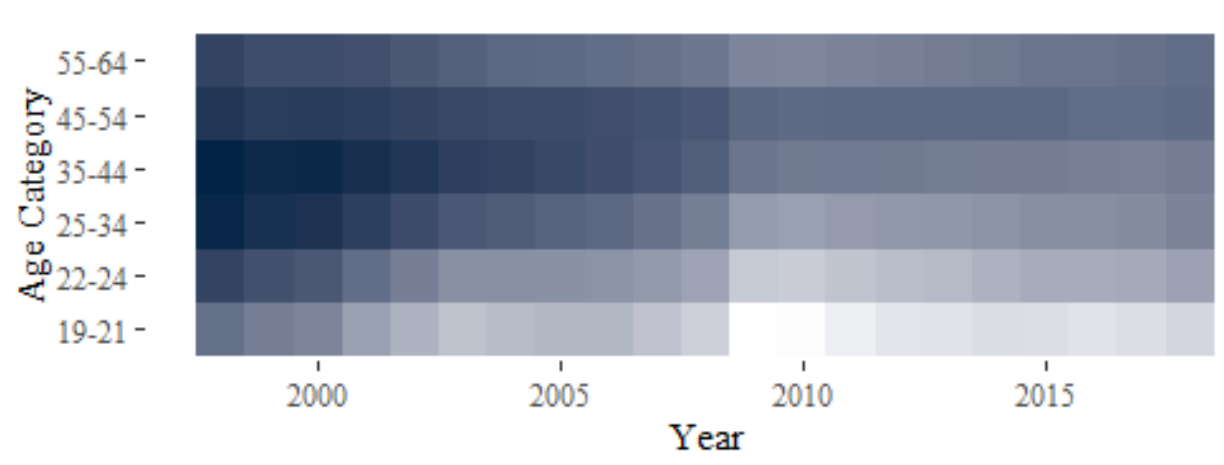

$\%$ Manufacturing Employment

Data: Census Bureau, Quarterly Workforce Indicators Dataset 
Figure 3. Annual County-Level Distribution of Percentage of Employment in Manufacturing, $1975-2016$

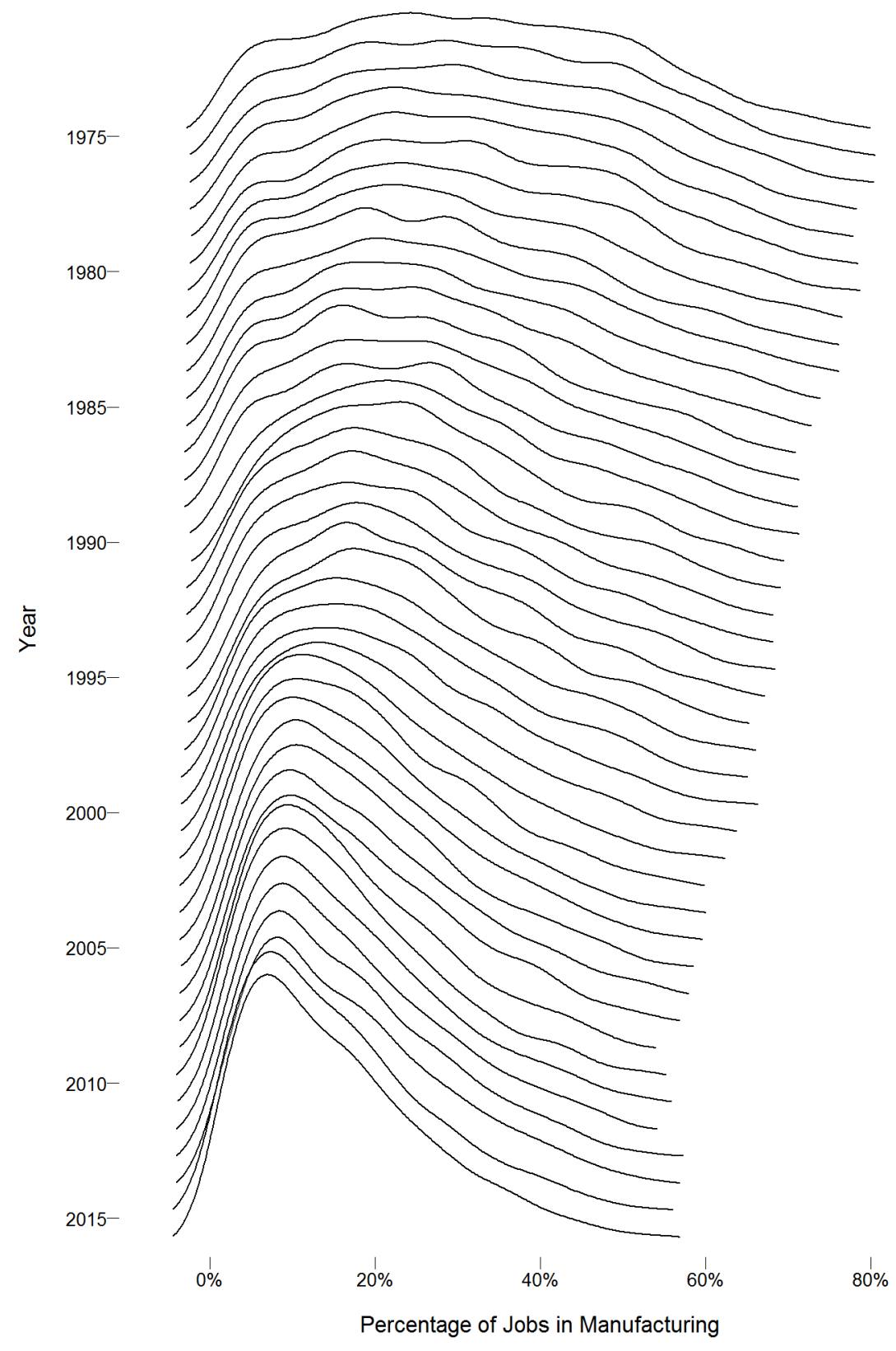

Notes: The average county percentage of manufacturing employment in 1980 was 28\%; in 1990, $23.5 \%$; in $2000,20.1 \%$; and in $2016,16.3 \%$. 
Figure 4. Map of the Percentage of All Jobs in County Labor Market in the Manufacturing Sector in 1998 and 2006

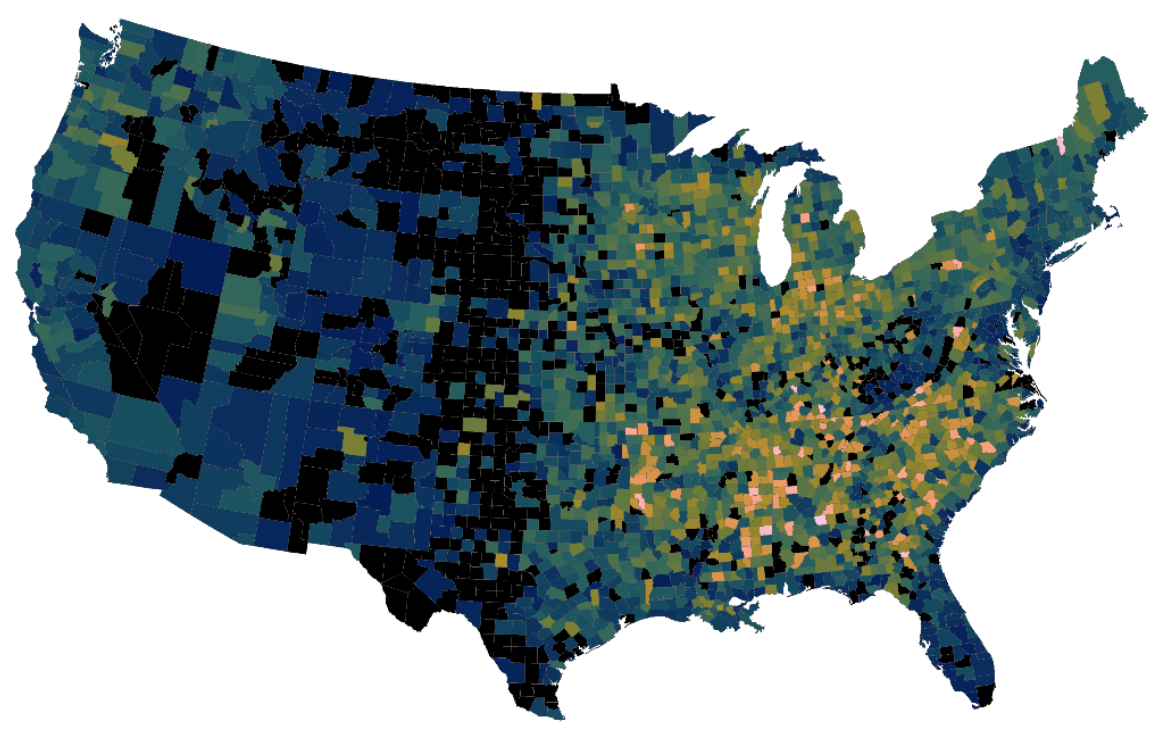

2006

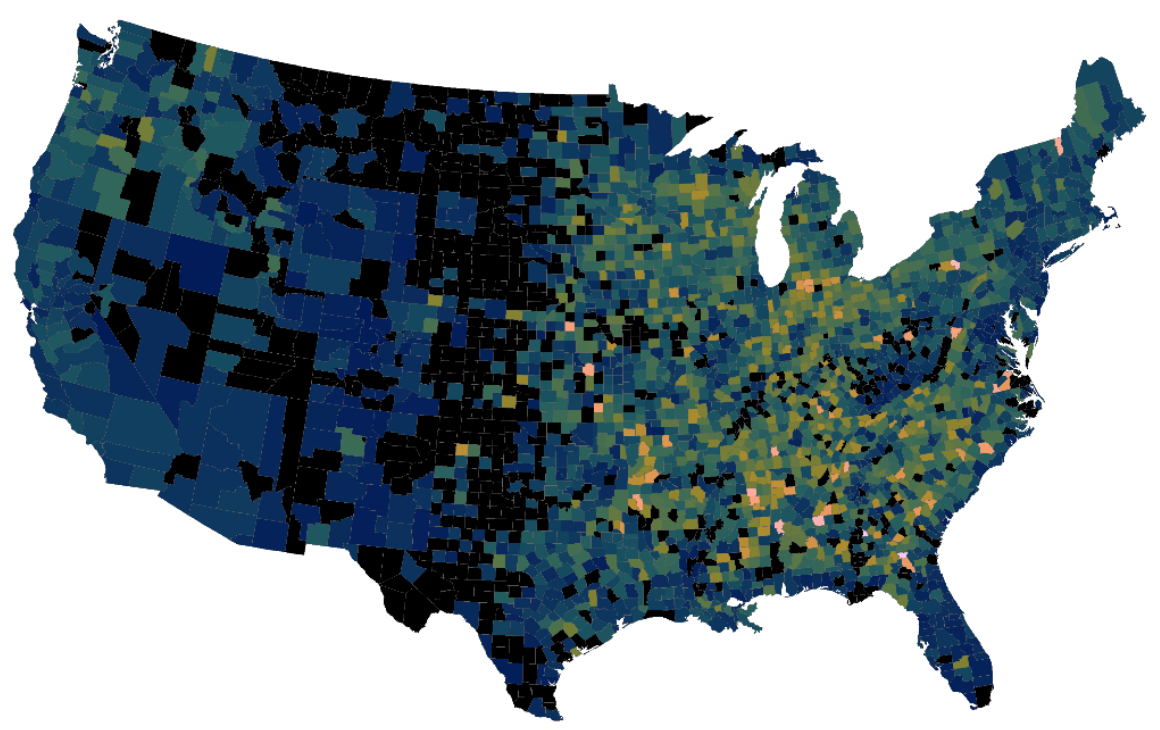

Percentage of Jobs

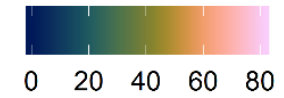


Notes: (a) Counties in black represent counties with missing data from the County Business Patterns dataset; (b) 1998 manufacturing employment corresponds to age 18 labor market entry for the 1980 birth cohort, while 2006 manufacturing employment corresponds to age 18 labor market entry for the 1988 birth cohort. 
Figure 5. Map of the Percentage Point Decline in Manufacturing Employment Between Birth and Labor Force Entry for 1980 and 1988 Birth Cohorts

\section{Birth Cohort}

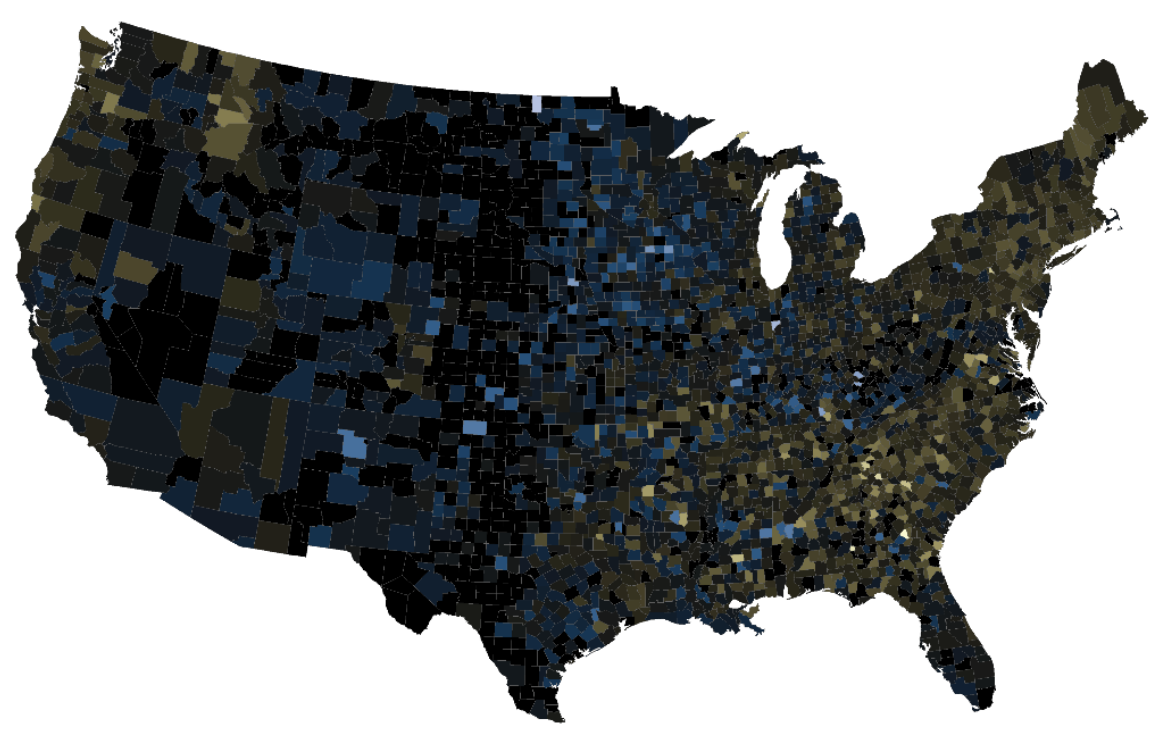

\section{Birth Cohort}

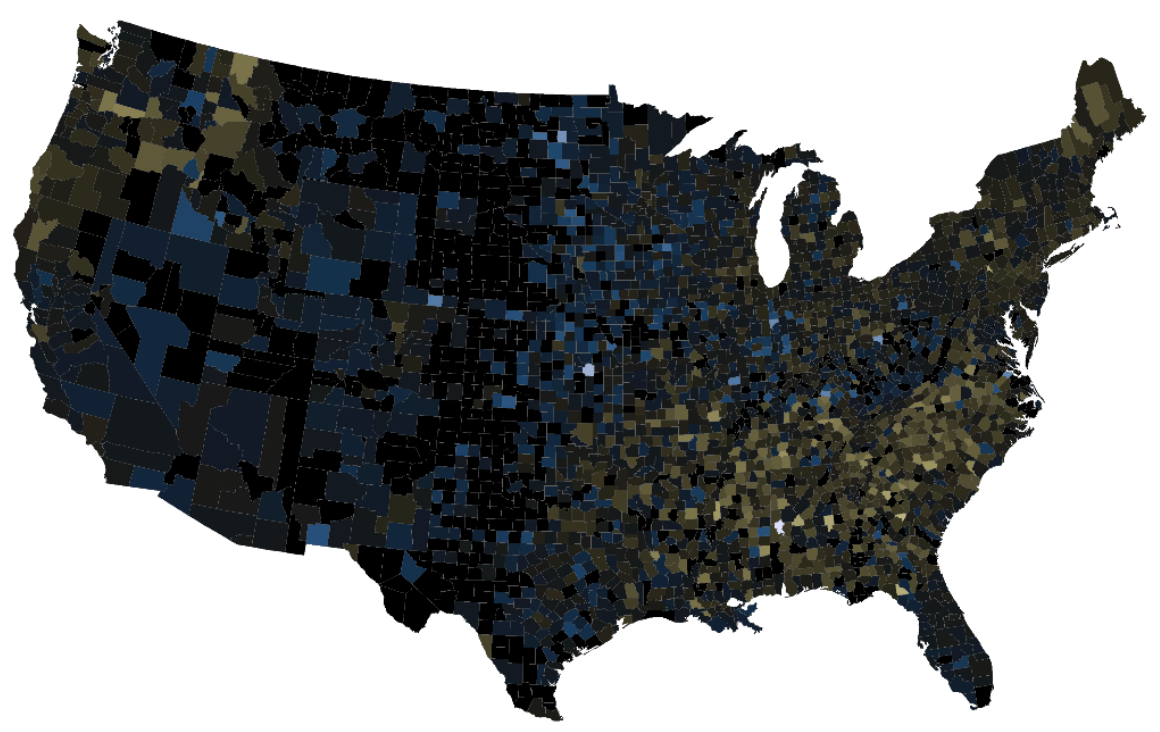

Percentage Point Decline in

Manufacturing Employment Between

Birth and Labor Force Entry

$\begin{array}{rllll}-50 & -25 & 0 & 25 & 50\end{array}$ 
Notes: (a) values are calculated as the difference between the percentage of manufacturing employment at birth and age 18; therefore, positive values represent declines in manufacturing employment while negative values represent increases in manufacturing employment; (b) Counties in black represent counties with missing data from the County Business Patterns dataset or counties with zero change. 
Figure 6. Models Predicting Intergenerational Income Mobility using Age Category Specific Measures of Manufacturing Employment

A. Rank in national household income distribution at age 24

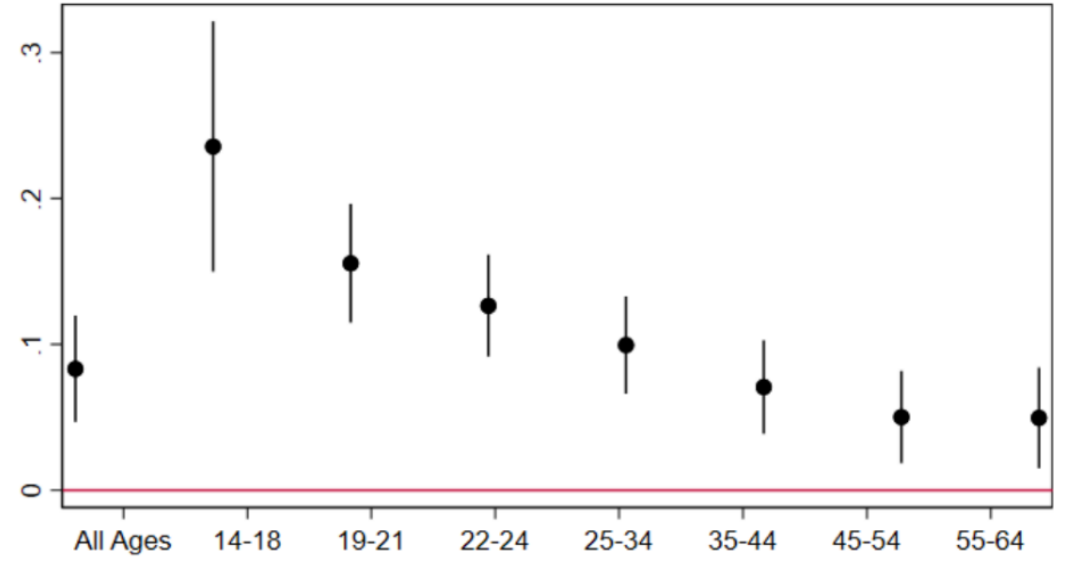

B. Rank-Rank Slope at age 24

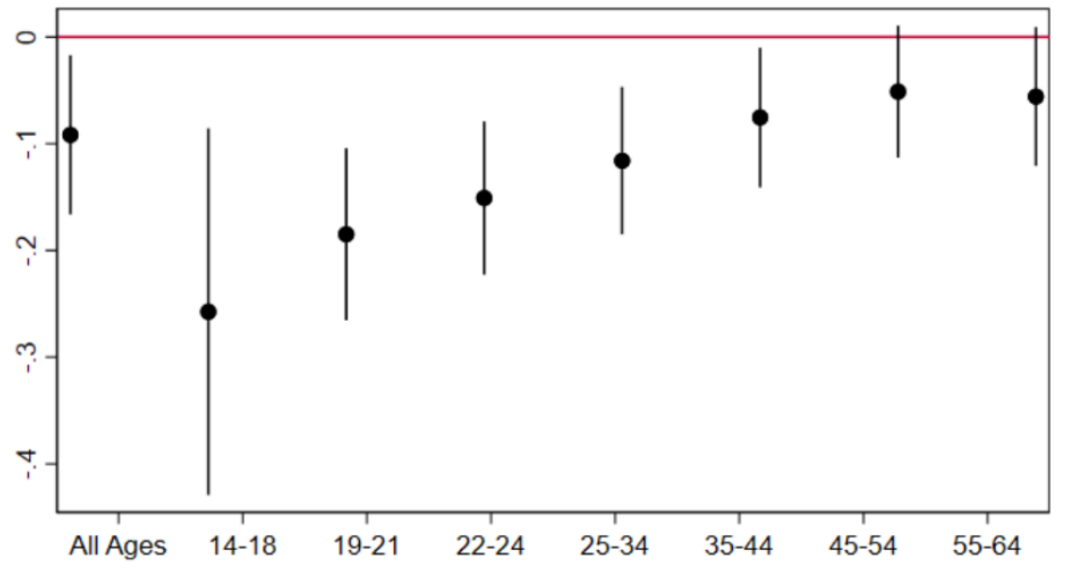


C. Rank in national household income distribution at age 26

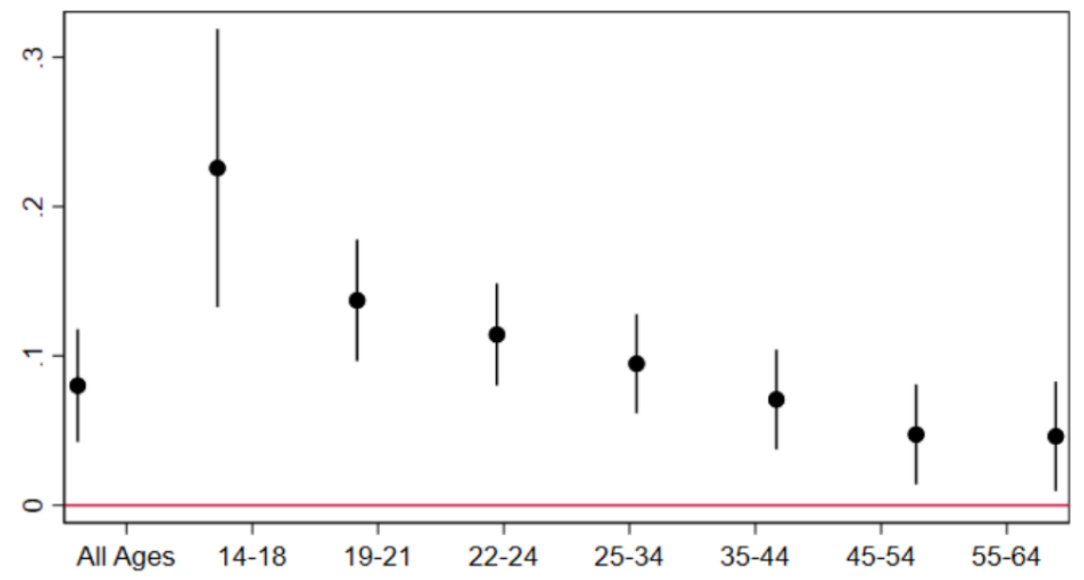

D. Rank-Rank Slope at age 26

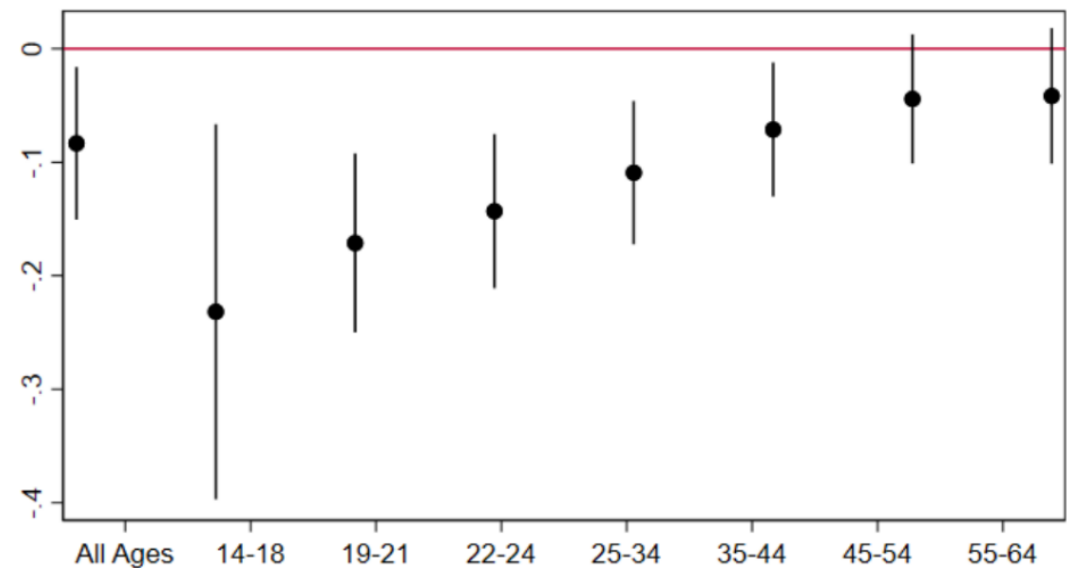

Notes: (a) all models include 9 separate cohorts born between 1980-1988 nested within each county; (b) Models are weighted by average within-county cohort size at age 18, (c) Standard errors clustered at the commuting zone, (d) covariates include birth cohort FE (for the age 24 and age 26 models), cohort population at age $18, \%$ of cohort black, county poverty rate, county logged per capita income adjusted to year 2000 dollars, county unemployment rate, county-level $\%$ with high school or less educational attainment, state-level \% of workers represented by labor unions, and county \% working age population and \% old age dependent population, (e) All covariates are time-varying for when cohort is age 18 . 


\section{APPENDIX}

Appendix Table 1. Comparison of Results for Age 26 Mobility Outcome Measure by Different Ages of Labor Market Entry

\begin{tabular}{|c|c|c|c|}
\hline \multirow[t]{2}{*}{ A. } & \multicolumn{3}{|c|}{ Absolute Upward Mobility } \\
\hline & Age 18 & Age 19 & Age 20 \\
\hline \multirow[t]{2}{*}{$\%$ Manufacturing } & $0.071 * * *$ & $0.081 * * *$ & $0.088 * * *$ \\
\hline & $(0.015)$ & $(0.016)$ & $(0.017)$ \\
\hline$\Delta$ Manufacturing & $-0.054 * * *$ & & \\
\hline (cohort: age $0-18$ ) & $(0.012)$ & & \\
\hline$\Delta$ Manufacturing & \multirow{2}{*}{\multicolumn{3}{|c|}{$\begin{array}{l}-0.054 * * * \\
(0.012)\end{array}$}} \\
\hline (cohort: age 0-19) & & & \\
\hline$\Delta$ Manufacturing & & & $-0.053 * * *$ \\
\hline (cohort: age $0-20$ ) & & & $(0.011)$ \\
\hline Observations & & 9169 & 9160 \\
\hline $\mathrm{R} 2$ & & 0.800 & 0.800 \\
\hline \multirow[t]{2}{*}{ B. } & \multicolumn{3}{|c|}{ Rank-Rank Slope } \\
\hline & Age 18 & Age 19 & Age 20 \\
\hline \multirow[t]{2}{*}{$\%$ Manufacturing } & $-0.071 *$ & $-0.080 * *$ & $-0.085^{* *}$ \\
\hline & $(0.028)$ & $(0.028)$ & $(0.028)$ \\
\hline$\Delta$ Manufacturing & $0.091 * * *$ & & \\
\hline (cohort: age $0-18$ ) & $(0.025)$ & & \\
\hline$\Delta$ Manufacturing & & $0.088 * * *$ & \\
\hline (cohort: age $0-19$ ) & & $(0.024)$ & \\
\hline$\Delta$ Manufacturing & & & $0.089 * * *$ \\
\hline (cohort: age 0-20) & & & $(0.023)$ \\
\hline Observations & 9179 & 9169 & 9160 \\
\hline $\mathrm{R} 2$ & 0.728 & 0.727 & 0.727 \\
\hline
\end{tabular}

Notes: (a) All right hand side variables are aligned to labor market characteristics at ages 18, 19, or 20 for each birth cohort, based on the column. 
Appendix Figure 1. Average Ages of Mothers (solid line) and Fathers (dashed line) for 19801988 Birth Cohorts when Cohort is 18 Years Old

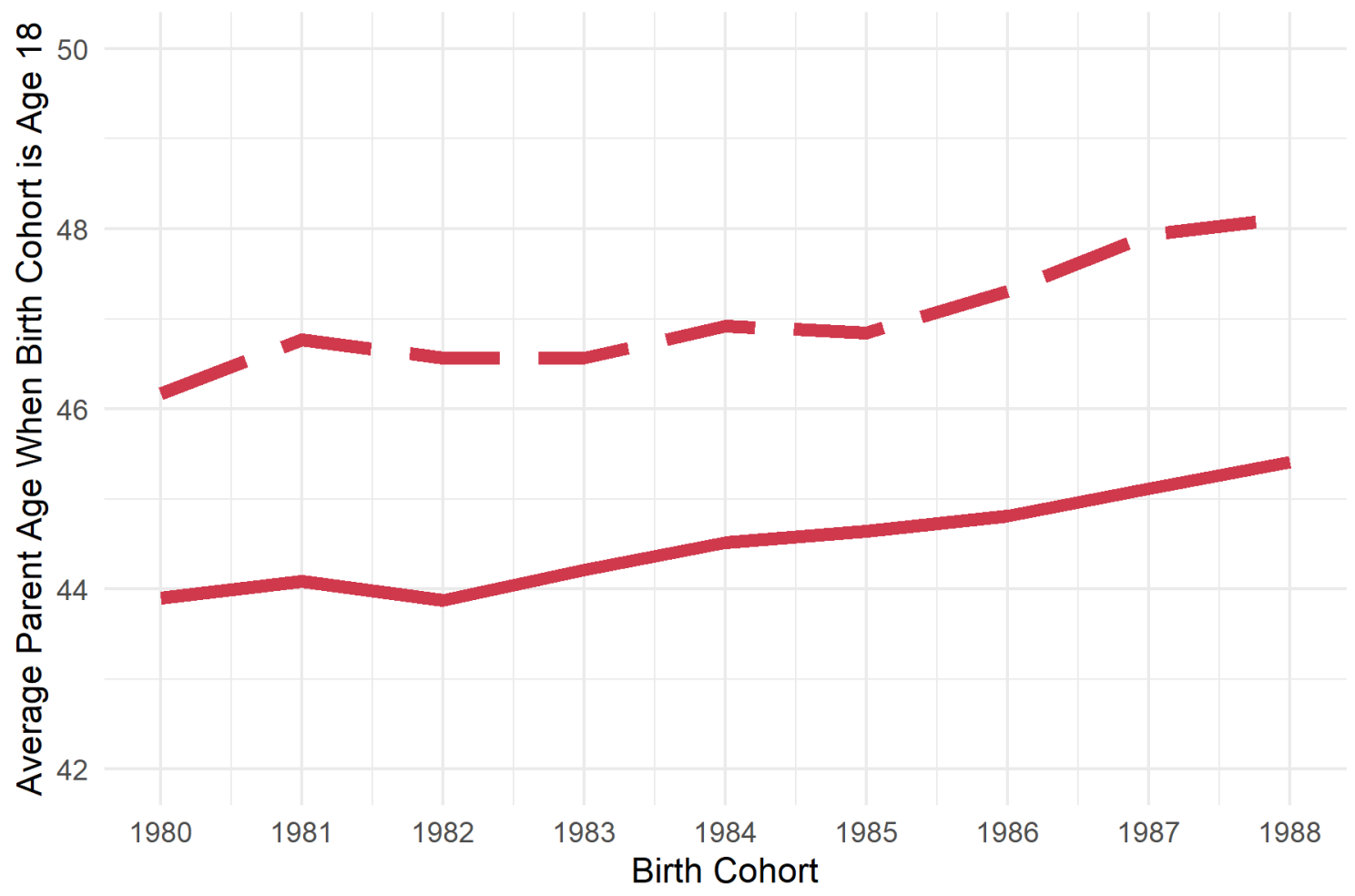

Notes: (1) Data are calculated from CPS ASEC; (2) Data are weighted using ASEC person weights. 